\title{
The molecular clock: a focus on chronopharmacological strategies for a possible control of aminoglycoside renal toxicity
}

This article was published in the following Dove Press journal:

ChronoPhysiology and Therapy

30 December 201I

Number of times this article has been viewed

\author{
Marcela Rebuelto \\ Farmacología, Facultad de Ciencias \\ Veterinarias, Universidad de Buenos \\ Aires, Buenos Aires, Argentina
}

\begin{abstract}
Chronotherapy applies biological rhythmicity in order to optimize clinical treatments, relating the dosing time of the drugs to the daily variations of their therapeutic and unwanted side effects due to the fluctuations in physiological processes involved in their pharmacokinetics and/or pharmacodynamics. The goal of chronotherapy is to administer treatments at the time of day that enhances both their effectiveness and tolerance. This review intends to (1) provide the theoretical rationale behind the use of aminoglycosides during extended interval schedule chronotherapy in clinical practice and (2) target the underlying molecular mechanisms of renal toxicity, the main unwanted side effect. Previous reports suggest that aminoglycoside therapy may benefit from a chronopharmacological approach. Temporal variations in the renal blood flow and glomerular filtration rate and several clock-dependent molecular mechanisms contributing to the daily changes in electrolyte and water urinary excretion have been reported. Daily differences in aminoglycoside toxicity and kinetic disposition have been found in laboratory animals and human patients. Nephrotoxicity and renal cortical accumulation are higher when drugs are administered during the rest phase than during the active phase. Active translocation of aminoglycosides into renal cells is mediated by the megalin/cubilin receptor complex located at the luminal epithelial cell membrane. The complex regulation of this endocytic mechanism deserves further study, in order to dilucidate the molecular bases that may be involved in chronotherapeutic strategies developed for minimizing aminoglycoside accumulation in the renal cells, and thus, increasing their tolerance.
\end{abstract}

Keywords: biological rhythms, chronopharmacology, chronotherapeutics, aminoglycosides

\section{Introduction}

Chronobiology studies the biological rhythms that are exhibited by physiological, behavioral, and biochemical functions in living beings, including bacteria, plants, and animals, and the structures that are related to them. ${ }^{1}$ A great number of functions of living organisms display a circadian (about 24-hour) rhythm. Circadian rhythms are organized by a master time-keeper: the internal clock. In mammals, this internal clock is located in the suprachiasmatic nuclei, ${ }^{2}$ and is synchronized to the environment primarily by the daily light-dark cycle. ${ }^{3}$ The molecular basis of circadian rhythms involves several interlocking transcriptional/translational feedback loops which induce the rhythmic expression of a set of clock-genes (BMAL, CLOCK, PER 1, PER 2, CRY 1, CRY 2, Rev-erb $\alpha$, Rev-erb $\beta$ ) and related clock-controlled genes (Dbp, Avp). ${ }^{4-6}$ The master central pacemaker synchronizes peripheral clocks, located in different tissues (liver, kidneys, lungs, heart, gastrointestinal tract). However, the primary synchronizer of these peripheral clocks is the feeding schedule (food-entrainable
Correspondence: Marcela Rebuelto Farmacología, Facultad de Ciencias Veterinarias, Universidad de Buenos Aires, Buenos Aires, Argentina

Tel +54 01 I 45248459

Email rebuelto@fvet.uba.ar 
peripheral oscillators), making possible the desynchronization of both central and peripheral clocks. ${ }^{7-10}$

Variability in the pharmacological response of medication may be the cause of therapeutic failure or result in the development of adverse effects. When the biological rhythms are included in the pharmacological studies, a new source of variability may be identified: the biological time. Chronopharmacology studies two aspects of drug administration: (1) the influence of the dosing time on the pharmacological response and (2) the effect of the drug on the biological rhythms, as the disturbance of the biological rhythms is currently considered an adverse effect. ${ }^{11-13}$ Biological time may affect the pharmacokinetics or pharmacodynamics of drugs, and thus, the pharmacological action. Chronokinetics and chronodynamics (chronoestesia) include in the experimental procedure the relevance of biological time, and identify the modifications in drug disposition or pharmacological effects, respectively, that may be due to the effects of biological rhythms on the involved physiological processes. The assessment of chronopharmacological changes require considerable effort, as experiments must be done at least in duplicate, in order to identify time of day-related changes, however, several studies have been reported. ${ }^{12,13}$

Chronokinetics rationale is based on the influence that the circadian oscillations have on several processes such as the absorption, distribution, elimination, and excretion of drugs, thus, the time of day that the drug is administered may produce different drug concentrations, even if the same dosing level is used. The identification of chronokinetic variations in therapeutic drugs is especially relevant when the desired effects are closely related to the drug concentrations, ie, antimicrobial agents. ${ }^{14}$ Chronodynamics is based on the circadian rhythms exhibited by receptors, ${ }^{15}$ thus affecting number and/or affinity of binding sites, leading to changes in the drug response. Chronotherapy applies a chronopharmacological approach to optimize clinical treatments, basing the dosing regimen on, if present, the daily variations of the pharmacokinetic and/or pharmacodynamic behaviors of the drug, and the temporal variations of the frequency and intensity of the pathophysiologic symptoms, administering the drug at the time that enhances both its effectiveness and tolerance.

The purpose of this review is to provide the theoretical rationale for a chronoptimized approach when using aminoglycosides in clinical practice, considering the molecular mechanisms underlying their renal toxicity.

\section{Chronotherapy: avoiding unwanted side effects}

Aminoglycoside antibiotics, including gentamicin, tobramycin, neomycin, and isepamicin, are antimicrobial agents that exhibit bactericidal activity against some Grampositive cocci, such as staphylococci, and Gram-negative bacilli such as Pseudomonas aeruginosa and Enterobacteriaceae. Antibacterial activity of aminoglycosides depends on high peak plasma concentrations, as they are concentration-dependent antibiotics. ${ }^{14}$ The mechanism of action of aminoglycosides is based on the high affinity for prokaryotic ribosomal RNA that these drugs possess, impairing bacterial protein synthesis and producing defective proteins that will ultimately lead to bacterial death. ${ }^{16}$ Aminoglycosides enter Gram-negative bacteria by crossing the outer membrane by means of an energy-dependent electron transporter. ${ }^{16}$ Gentamicin is an aminoglycoside that is useful in clinical practice, however, oto- and renal toxicities are the main limitations to its frequent use, and previous studies have related kidney lesions to high drug plasma concentrations during prolonged therapy. ${ }^{17}$ Gentamicin cytotoxicity produces extensive tubular damage and may induce serious adverse effects. ${ }^{18}$

It has been suggested that the once daily administration of gentamicin reduces the risk of developing nephrotoxicity over the two or three times daily administration in neonate, ${ }^{19}$ adult, ${ }^{20}$ and geriatric ${ }^{21}$ patients, probably related to the saturable mechanisms that transfer aminoglycosides into the proximal renal tubular epithelial cells..$^{20}$ This extended interval schedule may benefit from a chronotherapeutic approach, and the possible variations in the drug behavior related to the dosing time deserves exploration.

Several studies have demonstrated that time of administration may affect gentamicin-,${ }^{22-26}$ tobramycin-,${ }^{27-29}$ and isepamicin- ${ }^{30,31}$ induced toxicity in rats. ${ }^{32,33}$ Nephrotoxicity, evaluated by the excretion of renal enzymes ( $N$-acetyl- $\beta$-Dglucosaminidase and $\beta$-galactosidase), cortical and tubular cell lesions, blood urea nitrogen and serum creatinine level, and creatinine clearance, was maximal when the aminoglycoside was injected in the resting (day) compared to activity (night) phase in rats. ${ }^{22-31}$ This temporal variation was modified by the feeding time, renal toxicity being maximal when the drug was injected during the fasting period. ${ }^{23-25}$ Similar daily differences in aminoglycoside toxicity have been reported in human patients. Renal toxicity was more frequently observed when gentamicin or tobramycin were injected once daily during the night (rest) periods to patients with 
severe infections, when compared with early and late activity periods, even though no significant differences were found in peak or trough drug levels. ${ }^{34}$ This lack of difference in the disposition of the antibiotics may be related to the febrile status of the patients. It has been reported that fever erases diurnal variations in netilmicin excretion after its intravenous administration to severely infected human patients, probably due to the fever-induced changes in glomerular filtration. ${ }^{35}$ Using data previously obtained from human patients that had been treated with amikacin and developed renal toxicity, Rougier et a ${ }^{36}$ modelized aminoglycoside nephrotoxicity. The model developed showed that nephrotoxicity was lowest when the antibiotics were administered in the middle of the active period.

Even though the mechanisms underlying these temporal variations are not fully dilucidated, the pharmacokinetics of the drug may play an important role. Aminoglycosides are excreted mainly unchanged by the kidney, and accumulation of these antibiotics in the renal tubular cells is the main factor that determines their nephrotoxicity. Temporal variations in glomerular filtration and other renal functions may account for the lower drug elimination during the rest phase, producing higher renal accumulation and toxicity. ${ }^{37-41}$ A daily rhythm in the disposition of gentamicin, with significantly higher plasma and renal concentrations after its administration during the rest time in rats, has been reported previously. ${ }^{22,23}$ Similarly, dosing-time dependent variations on pharmacokinetic parameters have been described for tobramycin after its intravenous administration to rats. The area under the disposition curve was significantly smaller and clearance was significantly higher after its administration during the active phase. Tobramycin concentrations in the renal cortex were significantly lower during the activity phase than during the rest phase. This difference was related to differences in tobramycin serum levels ${ }^{27}$ and were lost when treatment was prolonged for 10 days. ${ }^{28}$ When isepamicin was administered at two different dosing times, cortical accumulation localized in the lysosomes of the cells of the renal proximal tubule was higher in rats treated during the rest phase than during the activity phase. ${ }^{30}$ Gentamicin plasma concentrations were lower following the morning compared to the night intravenous administration to dogs, and significant differences were found for several pharmacokinetic parameters. The initial concentration, mean residence time, and area under the disposition curve were higher and the apparent volume of distribution of the central compartment, apparent volume of distribution, apparent volume of distribution at steady-state, and total body clearance were lower following night administration than following morning administration, suggesting that gentamicin exhibits significant temporal variation in its kinetics when administered to dogs at different times of day. ${ }^{42}$ Similar diurnal variations of aminoglycoside disposition have been reported for human volunteers. For once daily administration, temporal differences in the pharmacokinetics of amikacin was reported in patients. ${ }^{43}$ The elimination rate constant was greater and the volume of distribution smaller for morning administration than evening administration. This suggests that amikacin may reach a higher peak and lower trough plasma levels when it is administered in the morning, favoring its therapeutic efficacy and safety ${ }^{43}$ Taken together, these studies provide evidence that time of day administration may be used to optimize aminoglycoside therapy. The data suggest that renal toxicity may be lower when the antibiotic is administered during the activity period. Moreover, it has been previously reported that in an experimental model of Escherichia coli-induced pyelonephritis in rats, gentamicin effectiveness, assessed by the number of microorganisms present in the kidneys and the percentage of sterile kidneys, was higher when the antibiotic was administered during the activity period. ${ }^{44}$ Thus, a chronotherapeutic approach may improve not only gentamicin renal tolerance but also antiinfective efficacy.

\section{Kidney function and the molecular circadian clock}

Until now, the pharmacological studies investigating the aminoglycosides nephrotoxicity have focused in chronokinetics, on the basis that the mechanisms of excretion of these drugs are more efficient during the activity period, due to temporal variations in the renal blood flow and glomerular filtration rate. ${ }^{37-41}$ In fact, the presence of clock genes has been demonstrated in rodent kidneys. The expression of BMAL1, CLOCK, PER 1, PER 2, and CRY 1 exhibits robust circadian rhythms in the kidneys of rats. This rhythmicity is affected by both the light/dark and feeding schedules, in a gene-specific pattern. ${ }^{45}$ The clock-controlled gene $D b p$ shows a clear circadian expression in the distal convoluted and collecting ducts of mouse kidneys.$^{46}$ Congruently, a circadian fluctuation has been reported on several excretory renal mechanisms. ${ }^{47}$ The key regulator of $\mathrm{Na}^{+}$reabsorption in the nephron distal portion is the epithelial $\mathrm{Na}^{+}$channel $(\mathrm{ENaC})$. The importance of the clock gene PER 1 in the transcriptional regulation of $\mathrm{ENaC}$ in the renal tissues has recently been reported. ${ }^{48} \mathrm{PER} 1$ 
deficient mice showed a significant decrease in ENaC mRNA levels compared with wild type control mice. Moreover, the 24-hour expression profile of ENaC mRNA exhibited a strong circadian pattern that was altered in PER 1 deficient mice, suggesting that the circadian clock regulates, at least partially, the ENaC mRNA expression in mice kidney. ${ }^{48}$ A previous study has demonstrated that genes ubiquitin specific protease Usp2 and glucocorticoid induced leucine zipper Gilz(Tsc22d3) involved in the regulation of transepithelial $\mathrm{Na}$ transport showed temporal differences in mice, fitting a 24-hour rhythm. ${ }^{46}$ The transmembrane protein $\mathrm{Na}^{+}$/ $\mathrm{H}^{+}$exchanger NHE3 plays a major role in mediating the $\mathrm{Na}^{+}$/ $\mathrm{H}^{+}$transporting activity in the proximal convoluted tubules and Henle's loop. It has been demonstrated that, in the mice kidney, NHE3 gene is transcriptionally controlled by clock genes PER 1 and PER 2, BMAL1, and CLOCK. ${ }^{49}$ Moreover, a circadian rhythm is clearly observed in both NHE mRNA and protein levels in the mice thick ascending and thin descending limbs of Henle's loop. ${ }^{50}$ Similarly, a circadian rhythm was identified in the expression of genes codifying vasopressin $\mathrm{V} 2$ and aquaporin apq-4 receptors, both involved in the renal homeostasis of water and sodium. ${ }^{46}$

Melatonin is a hormone cyclically produced, as the result of a well-characterized mechanism of inhibition and stimulation of its synthesis mediated by the retinal photoreceptors, which send information to the pineal gland about the diurnal changes of light intensity. ${ }^{51}$ Daily rhythms in melatonin production may synchronize several behavioral and physiological processes, transmitting photoperiodic signals to peripheral clocks. ${ }^{51}$ In vitro studies, using MadinDarby canine kidney (MDCK) cells, suggest that melatonin regulates the water transport mediated by the intercalated cells of the renal cortical collecting ducts. Thus, melatonin synchronizes kidney cell physiology with the photoperiod, resulting in maximal water transport from the apical to the basolateral membrane at night, simultaneously with the nocturnal rise of the hormone. ${ }^{52}$ In addition to the well-known role of melatonin in the synchronization of the biological clock, this hormone may play a unique role in the prevention of aminoglycoside nephro- and ototoxicity. ${ }^{53-57}$ It has been previously reported that gentamicin induces oxidative stress at both renal and vestibular cells in laboratory animals, and that the generation of high levels of reactive oxygen radical species (ROS) may be involved in the aminoglycoside toxicity. ${ }^{53-56}$ Melatonin significantly protected against gentamicin-induced renal ${ }^{53,54}$ and auditive ${ }^{56,57}$ tissue injury, due to its highly efficient free radical scavenger function and anti-apoptotic properties.
The presented data strongly suggest that all the above mentioned molecular mechanisms contribute to the daily changes in electrolyte and water urinary excretion. Similar circadian variations may be found on the renal excretion of some xenobiotics, as temporal profiles of gene expression levels in mice distal nephron segments and collecting ducts revealed the existence of diurnal expression changes for genes belonging to the superfamily of solute organic compound carriers (Slc6a9, Slc6a6, and Slc8a1) and to genes of several enzymes involved in the phase I and phase II metabolism of xenobiotics and other lipophilic compounds. ${ }^{46}$ These genes exhibited their maximal expression at the beginning of the activity period, thus demonstrating the anticipatory advantage of circadian rhythmicity.

Daily oscillations in aminoglycoside disposition due to temporal variations in the hemodynamic function of the kidney may not be the only biological mechanism involved in the different day/night nephrotoxicity of these drugs. There is an aspect that has yet to be studied, and it refers to the molecular mechanisms regulating the intracellular translocation of these drugs at the renal site. Even though aminoglycosides are freely filtered in the renal glomeruli, an endocytic mechanism mediates the translocation into the renal epithelial cell of a small percentage of the drug. Recent studies ${ }^{58-60}$ have demonstrated that the endocytic multiligand complex megalin/cubilin, located at the luminal surface of the proximal tubular cells, is involved in the uptake of a wide variety of compounds from the glomerular filtrate, such as albumin, vitamin D-binding protein and retinol-binding protein, and xenobiotics including aminoglycosides ${ }^{61,62}$ and radiolabeled peptides. ${ }^{63}$ Megalin is a transmembrane glycoprotein that belongs to the low-density lipoprotein (LDL) receptor family. Cubilin is a peripheral protein, lacking transmembrane and intracellular segments, anchored to the plasma membrane. ${ }^{59,64}$ Both receptors colocalize in the epithelial cells of the renal proximal tubule. Megalin represents the major pathway of aminoglycoside accumulation in the kidney, mediating their transfer to the lysosomes of the proximal tubular cell. ${ }^{18,61,62}$ Moreover, it has been demonstrated that megalin-deficient mice are protected from renal gentamicin accumulation. ${ }^{65}$ The mechanisms modulating the expression and activity of megalin are not yet completely dilucidated. Several compounds regulate megalin mRNA level expression, as retinoic acid, ${ }^{66}$ vitamin $\mathrm{D}$, angiotensin II, bile acids, ${ }^{67}$ and the nuclear receptor transcriptional factor peroxisomal proliferator-activated receptor (PPAR $\alpha) \cdot{ }^{68}$ Megalin folding is controlled by the specialized chaperones receptor associated protein (RAP) and mesodermal development candidate 
(MESD), and the cytosolic adaptator protein Dab2 and the glycogen synthase kinase-type 3 (GSK3) are also important in megalin expression and trafficking. ${ }^{67}$ This complex regulatory mechanism may exhibit circadian rhythmicity in one or more of its steps, thus conferring temporal differences to megalin availability and/or functionality. There is emerging evidence of the existence of clear connections between the molecular mechanisms of the mammalian circadian clock and several nuclear receptors. ${ }^{69-72}$ In fact, experiments performed with human and monkey kidney cells suggest that PPARs and clock genes cross regulate each other at the transcription level. ${ }^{71}$ A reciprocal regulation between PPARs and clock genes has been shown in peripheral tissues. CLOCK/BMAL1 regulates the circadian expression of PPAR $\alpha$ whereas PPAR $\alpha$ affects transcription of BMAL1. ${ }^{73-75}$ A circadian regulation by clock protein PER 2 repressing PPAR $\gamma$ transcriptional activity has been described for lipid metabolism. ${ }^{76,77}$ PPAR $\gamma$ mRNA is expressed in an oscillatory pattern in Caco 2 cells. ${ }^{78}$ In mouse liver, the expression profile of PPAR $\alpha$ showed a clock-dependent circadian expression, this is in turn reflected by the circadian oscillations of the PPAR-dependent fibroblast growth factor 21 (FGF21). ${ }^{73,74}$ Diurnal variation of mouse liver PPAR $\alpha$ is abolished in clock-mutant mice. ${ }^{73}$ A circadian rhythmicity was found for the PPAR $\alpha$ expression in white and brown adipose tissue in liver, but not in skeletal muscle, of mice. This rhythm is tissue-specific, with different peak levels in brown adipose tissue, white adipose tissue, and liver. ${ }^{79}$

To the author's knowledge, studies describing 24-hour megalin temporal levels have not been reported. However, megalin belongs to the LDL-receptor family and thus, it may display circadian rhythmicity at the mRNA, protein expression, or functional activity levels. In a previous study, hepatic LDL-receptor activity exhibited its maximum at the onset of darkness, in accordance with the food intake, whereas the minimum value was observed during the light period. ${ }^{80}$ Congruently, mice exhibited clear rhythmicity in liver $L d l r$ gene expression; this rhythmicity was abolished in clock-mutant mice. ${ }^{81}$ Moreover, (NHE)3, whose transcription is clock-controlled, ${ }^{49}$ exists in the apical membrane of the proximal renal tubule as a molecular complex in association with megalin. ${ }^{82}$

\section{Final considerations}

Taken together, the previous studies hereby described suggest that many physiological renal functions display a circadian rhythm at least at mRNA expression levels, and some of these different temporal patterns are also expressed at the functional activity level. There is extensive evidence, albeit in non-renal tissues, reporting circadian rhythms in PPAR $\alpha$ and PPAR $\gamma$, a known modulator of megalin. In addition, hepatic LDL receptors express daily rhythms. Based on the molecular mechanisms underlying the cellular uptake of aminoglycosides in the kidney, megalin activity can be a critical factor contributing to aminoglycosideinduced renal toxicity. If the renal LDL receptor megalin expresses daily oscillations, as happens in the liver, it may be at least partially involved in the temporal variations of aminoglycosides nephrotoxicity. Further studies on megalin and cubilin activity during a circadian cycle should clarify this assumption, and the time of administration may be one factor to consider in reducing the incidence of unwanted side effects from aminoglycoside.

\section{Acknowledgments}

Dr M Rebuelto's work on antibiotics is supported by grant UBACYT 2011-2013, University of Buenos Aires. The author thanks the editor of ChronoPhysiology and Therapy for the invitation to write this review, and to the anonymous reviewers who provided useful suggestions for improving this paper.

\section{Disclosure}

The author reports no conflict of interest in this work.

\section{References}

1. Halberg F. Chronobiology. Annu Rev Physiol. 1969;31:675-725.

2. Ralph MR, Foster RG, Davis FC, Menaker M. Transplanted suprachiasmatic nucleus determines circadian period. Science. 1990; 247(4945):975-978.

3. Muñoz M, Peirson SN, Hankins MW, Foster RG. Long-term constant light induces constitutive elevated expression of mPER2 protein in the murine SCN: a molecular basis for Aschoff's rule? J Biol Rhythms. 2005;20(1):3-14.

4. Albrecht U. Invited review: regulation of mammalian circadian clock genes. J Appl Physiol. 2002;92(3):1348-1355.

5. Cermakian N, Boivin DB. A molecular perspective of human circadian rhythm disorders. Brain Res Rev. 2003;42(3):204-220.

6. Hastings MH, Herzog ED. Clock genes, oscillators, and cellular networks in the suprachiasmatic nuclei. J Biol Rhythms. 2004;19(5):400-413.

7. Damiola F, Le Minh N, Preitner N, Kornmann B, Fleury-Olela F, Schibler U. Restricted feeding uncouples circadian oscillators in peripheral tissues from the central pacemaker in the suprachiasmatic nucleus. Genes Dev. 2000;14(23):2950-2961.

8. Hirao J, Arakawa S, Watanabe K, Ito K, Furukawa T. Effects of restricted feeding on daily fluctuations of hepatic functions including p450 monooxygenase activities in rats. J Biol Chem. 2006;281(6): 3165-3171.

9. Sheward WJ, Maywood ES, French KL, et al. Entrainment to feeding but not to light: circadian phenotype of VPAC2 receptor-null mice. J Neurosci. 2007;27(16):4351-4358.

10. Hayashi Y, Ushijima K, Ando H, et al. Influence of a time-restricted feeding schedule on the daily rhythm of abcbla gene expression and its function in rat intestine. J Pharmacol Exp Ther. 2010;335(2):418-423. 
11. Reinberg AE. Concepts in chronopharmacology. Annu Rev Pharmacol Toxicol. 1992;32:51-66.

12. Ritschel WA, Forusz H. Chronopharmacology, a review of drugs studied. Methods Find Exp Clin Pharmacol. 1994;16(1):57-75.

13. Bruguerolle B. Chronopharmacokinetics. Current status. Clin Pharmacokinet. 1998;35(2):83-94.

14. Drusano GL. Antimicrobial pharmacodynamics: critical interactions of 'bug and drug'. Nat Rev Microbiol. 2004;2(4):289-300.

15. Wirz-Justice A. Circadian rhythms in mammalian neurotransmitter receptors. Prog Neurobiol. 1987;29(3):219-259.

16. Mingeot-Leclercq MP, Glupczynski Y, Tulkens PM. Aminoglycosides: activity and resistance. Antimicrob Agents Chemother. 1999;43(4): 727-737.

17. Prins JM, Weverling GJ, de Blok K, van Ketel RJ, Speelman P. Validation and nephrotoxicity of a simplified once-daily aminoglycoside dosing schedule and guidelines for monitoring therapy. Antimicrob Agents Chemother. 1996;40(11):2494-2499.

18. Quiros Y, Vicente-Vicente L, Morales AI, López-Novoa JM, LópezHernández FJ. An integrative overview on the mechanisms underlying the renal tubular cytotoxicity of gentamicin. Toxicol Sci. 2011;119(2): $245-256$.

19. Rao SC, Ahmed M, Hagan R. One dose per day compared to multiple doses per day of gentamicin for treatment of suspected or proven sepsis in neonates. Cochrane Database Syst Rev. 2006;25(1):CD005091.

20. Rybak MJ, Abate BJ, Kang SL, Ruffing MJ, Lerner SA, Drusano GL. Prospective evaluation of the effect of an aminoglycoside dosing regimen on rates of observed nephrotoxicity and ototoxicity. Antimicrob Agents Chemother. 1999;43(7):1549-1555.

21. Bourguignon L, Goutelle S, De Saint-Martin JB, Maire P, Ducher M. Evaluation of various gentamicin dosage regimens in geriatric patients: a simulation study. Fundam Clin Pharmacol. 2010;24(1):109-113.

22. Yoshiyama Y, Kobayashi T, Tomonaga F, Nakano S. Chronotoxical study of gentamicin induced nephrotoxicity in rats. J Antibiot (Tokyo). 1992;45(5):806-808.

23. Beauchamp D, Collin P, Grenier L, et al. Effects of fasting on temporal variation in nephrotoxicity of gentamicin in rats. Antimicrob Agents Chemother. 1996;40(3):670-676.

24. Beauchamp D, Guimont C, Grenier L, et al. Time-restricted feeding schedules modify temporal variation of gentamicin experimental nephrotoxicity. Antimicrob Agents Chemother. 1997;41(7): $1468-1474$

25. Julien N, Karzasi M, Labrecque G, Beauchamp D, Thibault L. Temporal modulation of nephrotoxicity, feeding, and drinking in gentamicintreated rats. Physiol Behav. 2000;68(4):533-541.

26. Paquette M, Plante I, Labrecque G, Beauchamp D, Thibault L. Dietary composition alters gentamicin-induced nephrotoxicity in rats. Physiol Behav. 2002;77(1):141-150.

27. Lin L, Grenier I, Bergeron Y, et al. Temporal changes of pharmacokinetics, nephrotoxicity and subcellular distribution of tobramycin in rats. Antimicrob Agents Chemother. 1994;38(1):54-60.

28. Lin L, Grenier L, Theriault G, et al. Nephrotoxicity of low doses of tobramycin in rats: effect of the time of administration. Life Sci 1994; 55(3):169-177.

29. Lin L, Grenier L, Guimont C, et al. Circadian variation in the intracortical accumulation kinetics of tobramycin in conscious rats. Chronobiol Int. 1995;12(3):188-194.

30. Yoshiyama Y, Nishikawa S, Sugiyama T, et al. Influence of circadian-stage-dependent dosing schedule on nephrotoxicity and pharmacokinetics of isepamicin in rats. Antimicrob Agents Chemother. 1993;37(9):2042-2053.

31. Yoshiyama Y, Grenier L, Gourde P, et al. Temporal variation in nephrotoxicity of low doses of isepamicin in rats. Antimicrob Agents Chemother. 1996;40(3):802-806.

32. Beauchamp D, Labrecque G. Aminoglycoside nephrotoxicity: do time and frequency of administration matter? Curr Opin Crit Care. 2001;7(6): 401-408.
33. Beauchamp D, Labrecque G. Chronobiology and chronotoxicology of antibiotics and aminoglycosides. Adv Drug Deliv Rev. 2007;59(9-10): 896-903.

34. Prins JM, Weverling GJ, van Ketel RJ, Speelman P. Circadian variations in serum levels and the renal toxicity of aminoglycoside in patients. Clin Pharmacol Ther. 1997;62(1):106-1011.

35. Fauvelle F, Perrin P, Belfayol L, et al. Fever and associated changes in glomerular filtration rate erase anticipated diurnal variations in aminoglycoside pharmacokinetics. Antimicrob Agents Chemother. 1994;38(3):620-623.

36. Rougier F, Claude D, Maurin M, et al. Aminoglycoside nephrotoxicity: modeling, simulation, and control. Antimicrob Agents Chemother. 2003; 47(3):1010-1016.

37. Pons M, Forpomés O, Espagnet S, Cambar J. Relationship between circadian changes in renal hemodynamics and circadian changes in urinary glycosaminoglycan excretion in normal rats. Chronobiol Int. 1996;13(5):349-358.

38. Pons M, Schnecko A, Witte K, Lemmer B, Waterhouse JM, Cambar J. Circadian rhythms in renal function in hypertensive TGR (mRen-2) rats and their normotensive controls. Am J Physiol 1996;271(4 Pt 2): R1002-R1008.

39. Pons M, Mellado M, Cambar J. Effects of cyclosporin A on circadian changes in urinary water, sodium and potasium excretion in conscious unrestained chronically cannulated rats. Biol Rythms Res. 1997;28:56-68.

40. Voogel AJ, Koopman MG, Hart AA, van Montfrans GA, Arisz L. Circadian rhythms in systemic hemodynamics and renal function in healthy subjects and patients with nephrotic syndrome. Kidney Int. 2001;59(5):1873-1880.

41. Kamperis K, Hansen MN, Hagstroem S, Hvistendahl G, Djurhuus JC, Rittig S. The circadian rhythm of urine production, and urinary vasopressin and prostaglandin E2 excretion in healthy children. $J$ Urol. 2004;171(6 Pt 2):2571-2575.

42. Widerhon N, Díaz D, Picco E, Rebuelto M, Encinas T, Carlos Boggio J. Chronopharmacokinetic study of gentamicin in dogs. Chronobiol Int. 2005;22(4):731-739.

43. Bleyzac N, Allard-Latour B, Laffont A, Mouret J, Jelliffe R, Maire P. Diurnal changes in the pharmacokinetic behavior of amikacin. Ther Drug Monit. 2000;22(3):307-312.

44. LeBrun M, Grenier L, Gourde P, Bergeron M, Labrecque G, Beauchamp D. Effectiveness and toxicity of gentamicin in an experimental model of pyelonephritis: effect of the time of administration. Antimicrob Agents Chemother. 1999;43(5):1020-1026.

45. Wu T, Ni Y, Dong Y, et al. Regulation of circadian gene expression in the kidney by light and food cues in rats. Am J Physiol Regul Integr Comp Physiol. 2010;298(3):R635-R641.

46. Zuber AM, Centeno G, Pradervand S, et al. Molecular clock is involved in predictive circadian adjustment of renal function. Proc Natl Acad Sci U S A. 2009;106(38):16523-16528.

47. Firsov D, Tokonami N, Bonny O. Role of the renal circadian timing system in maintaining water and electrolytes homeostasis. Mol Cell Endocrinol. 2011. doi: 10.1016/j.mce.2011.06.037.

48. Gumz ML, Stow LR, Lynch IJ, et al. The circadian clock protein Period 1 regulates expression of the renal epithelial sodium channel in mice. J Clin Invest. 2009;119(8):2423-2434.

49. Saifur Rohman M, Emoto N, Nonaka H, et al. Circadian clock genes directly regulate expression of the $\mathrm{Na}(+) / \mathrm{H}(+)$ exchanger NHE3 in the kidney. Kidney Int. 2005;67(4):1410-1419.

50. Nishinaga H, Komatsu R, Doi M, et al. Circadian expression of the $\mathrm{Na}+\mathrm{H}+$ exchanger NHE3 in the mouse renal medulla. Biomed Res. 2009;30(2):87-93.

51. Reiter RJ, Tan DX, Fuentes-Broto L. Melatonin: a multitasking molecule. Prog Brain Res. 2010;181:127-151.

52. Ramirez-Rodríguez G, Meza I, Hernández ME, Castillo A, BenítezKing G. Melatonin induced cyclic modulation of vectorial water transport in kidney-derived MDCK cells. Kidney Int. 2003;63(4):1356-1364. 
53. Ozbek E, Turkoz Y, Sahna E, Ozugurlu F, Mizrak B, Ozbek M. Melatonin administration prevents the nephrotoxicity induced by gentamicin. BJU Int. 2000;85(6):742-746.

54. Sener G, Sehirli AO, Altunbas HZ, et al. Melatonin protects against gentamicin-induced nephrotoxicity in rats. J Pineal Res. 2002;32(4): 231-236.

55. Parlakpinar H, Ozer MK, Sahna E, Vardi N, Cigremis Y, Acet A Amikacin-induced acute renal injury in rats: protective role of melatonin. $J$ Pineal Res. 2003;35(2):85-90.

56. Kim JB, Jung JY, Ahn JC, Rhee CK, Hwang HJ. Antioxidant and antiapoptotic effect of melatonin on the vestibular hair cells of rat utricles. Clin Exp Otorhinolaryngol. 2009;2(1):6-12.

57. Reiter RJ, Tan DX, Korkmaz A, Fuentes-Broto L. Drug-mediated ototoxicity and tinnitus: alleviation with melatonin. J Physiol Pharmacol. 2011;62(2):151-157.

58. Odera K, Goto S, Takahashi R. Age-related change of endocytic receptors megalin and cubilin in the kidney in rats. Biogerontology. 2007;8(5):505-515.

59. Christensen EI, Verroust PJ, Nielsen R. Receptor-mediated endocytosis in renal proximal tubule. Pflugers Arch. 2009;458(6):1039-1048.

60. Saito A, Sato H, Iino N, Takeda T. Molecular mechanisms of receptormediated endocytosis in the renal proximal tubular epithelium. J Biomed Biotechnol. 2010;2010:403272.

61. Moestrup SK, Cui S, Vorum H, et al. Evidence that epithelial glycoprotein 330/megalin mediates uptake of polybasic drugs. J Clin Invest. 1995;96(3):1404-1413.

62. Antoine DJ, Srivastava A, Pirmohamed M, Park BK. Statins inhibit aminoglycoside accumulation and cytotoxicity to renal proximal tubule cells. Biochem Pharmacol. 2010;79(4):647-654.

63. Vegt E, Melis M, Eek A, et al. Renal uptake of different radiolabelled peptides is mediated by megalin: SPECT and biodistribution studies in megalin-deficient mice. Eur J Nucl Med Mol Imaging. 2011; 38(4):623-632.

64. Verroust PJ, Kozyraki R. Cubilin: physiopathologic role and relationship with megalin. Med Sci (Paris). 2003;19(3):337-343. French.

65. Schmitz C, Hilpert J, Jacobsen C, et al. Megalin deficiency offers protection from renal aminoglycoside accumulation. J Biol Chem. 2002; 277(1):618-622.

66. Chlon TM, Taffany DA, Welsh J, Rowling MJ. Retinoids modulate expression of the endocytic partners megalin, cubilin, and disabled-2 and uptake of vitamin D-binding protein in human mammary cells. J Nutr. 2008;138(7):1323-1328.

67. Marzolo MP, Farfán P. New insights into the roles of megalin/LRP2 and the regulation of its functional expression. Biol Res. 2011;44(1): 89-105.
68. Cabezas F, Lagos J, Céspedes C, Vio CP, Bronfman M, Marzolo MP Megalin/LRP2 expression is induced by peroxisome proliferatoractivated receptor -alpha and -gamma: implications for PPARs' roles in renal function. PLoS One. 2011;6(2):e16794.

69. Teboul M, Gréchez-Cassiau A, Guillaumond F, Delaunay F. How nuclear receptors tell time. J Appl Physiol. 2009;107(6):1965-1971.

70. Yang X. A wheel of time: the circadian clock, nuclear receptors, and physiology. Genes Dev. 2010;24(8):741-747.

71. Nakamura K, Inoue I, Takahashi S, Komoda T, Katayama S. Cryptochrome and period proteins are regulated by the CLOCK BMAL1 gene: crosstalk between the PPARs/RXRalpha-Regulated and CLOCK/BMAL1-regulated systems. PPAR Res. 2008;2008:348610.

72. Schmutz I, Ripperger JA, Baeriswyl-Aebischer S, Albrecht U. The mammalian clock component PERIOD2 coordinates circadian output by interaction with nuclear receptors. Genes Dev. 2010;24(4):345-357.

73. Oishi K, Shirai H, Ishida N. CLOCK is involved in the circadiantransactivation of peroxisome-proliferator-activated receptor alpha (PPARalpha) in mice. Biochem J. 2005;386(Pt 3):575-581.

74. Oishi K, Uchida D, Ishida N. Circadian expression of FGF21 is induced by PPARalpha activation in the mouse liver. FEBS Lett. 2008;582(25-26):3639-3642.

75. Charoensuksai $\mathrm{P}, \mathrm{Xu}$ W. PPARs in rhythmic metabolic regulation and implications in health and disease. PPAR Res. 2010;2010. pii: 243643.

76. Grimaldi B, Bellet MM, Katada S, et al. PER2 controls lipid metabolism by direct regulation of PPAR $\gamma$. Cell Metab. 2010;12(5):509-520.

77. Inoue I, Shinoda Y, Ikeda M, et al. CLOCK/BMAL1 is involved in lipidmetabolism via transactivation of the peroxisome proliferatoractivated receptor (PPAR) response element. J Atheroscler Thromb. 2005;12(3):169-174.

78. Takahashi S, Inoue I, Nakajima Y, et al. A promoter in the novel exon of hPPARgamma directs the circadian expression of PPARgamma. $J$ Atheroscler Thromb. 2010;17(1):73-83.

79. Yang X, Downes M, Yu RT, et al. Nuclear receptor expression links the circadian clock to metabolism. Cell. 2006;126(4):801-810.

80. Balasubramaniam S, Szanto A, Roach PD. Circadian rhythm in hepatic low-density-lipoprotein (LDL)-receptor expression and plasma LDL levels. Biochem J. 1994;298(Pt 1):39-43.

81. Kudo T, Kawashima M, Tamagawa T, Shibata S. Clock mutation facilitates accumulation of cholesterol in the liver of mice fed a cholesterol and/or cholic acid diet. Am J Physiol Endocrinol Metab. 2008;294(1):E120-E130.

82. Biemesderfer D, Nagy T, DeGray B, Aronson PS. Specific association of megalin and the $\mathrm{Na}+\mathrm{H}+$ exchanger isoform NHE3 in the proximal tubule. J Biol Chem. 1999;274(25):17518-17524.
ChronoPhysiology and Therapy

\section{Publish your work in this journal}

ChronoPhysiology and Therapy is an international, peer-reviewed, open access journal focusing on research into the cyclic variations and rhythmicity in physiological processes in the body and the research and development and optimal timing of administration of therapeutic targets to achieve improved outcomes and quality of life for the patient. The

\section{Dovepress}

manuscript management system is completely online and includes a very quick and fair peer-review system. Visit http://www.dovepress.com/ testimonials.php to read real quotes from published authors. 